\title{
Convergências teóricas em representações sociais e seu aporte para o estudo de políticas docentes
}

\author{
Theoretical convergences in social representations and its \\ contribution for teacher's policies studies
}

Convergencia en la teoría en las representaciones sociales y su contribución para el estudio de las políticas docentes

\section{Adelina Novaes $^{[a]}$, Maria de Lourdes Ornellas ${ }^{[b]}$, Romilda Teodora Ens ${ }^{[c]^{*}}$}

[a] Fundação Carlos Chagas/ UNICID, São Paulo, SP, Brasil

[b] Universidade do Estado da Bahia, Salvador, BA, Brasil

[c] Pontifícia Universidade Católica do Paraná, Curitiba, PR, Brasil

\section{Resumo}

Os debates que compõem este artigo visam proporcionar uma análise acerca das potencialidades que a teoria das representações sociais (TRS) oferece às pesquisas em políticas docentes. Por meio da consideração de duas das abordagens teórico-metodológicas que compõem o domínio dos estudos em representações sociais, buscou-se identificar convergências teóricas que instrumentalizassem as pesquisas em políticas públicas. Os estudos

* AN: Doutora em educação, e-mail: adelnovaes@gmail.com

MLO: Doutora em psicologia da educação, e-mail: ornellas1@terra.com.br

RTE: Doutora em educação, e-mail: romilda.ens@gmail.com 
da abordagem processual inquietaram os paradigmas da ciência moderna e criaram um estilo original em que a ênfase na subjetividade presentifica o conceito de sujeito e de objeto, uma vez que ambos compartilham de uma relação de construção mútua, na qual a realidade se constrói. Por outro lado, a abordagem dialógica proposta por Ivana Marková oferece um profícuo aparato para a compreensão da constituição social dos sujeitos que convivem nos contextos educacionais. A convergência teórica das abordagens discutidas contribuiu para a identificação da TRS enquanto uma vertente do conhecimento científico que fomenta a análise das políticas docentes, por oferecer constructos para o estudo das simbolizações expressas nos documentos, bem como daquelas circulantes nos diferentes grupos por meio das conversações e das práticas.

Palavras-chave: Representações Sociais. Educação. Processual. Dialogicidade. Abordagens teóricas. Políticas Docentes.

\section{Abstract}

Discussions who make up this article intended to provide an analysis of the potential which the theory of social representations (TSR) offers to the researches on teacher policies. Through the consideration of two of the theoretical and methodological approaches that make up the field of studies on social representations, the paper sought to identify theoretical convergences that offered instruments to the research on public policy. The studies on procedural approach disturbed the paradigms of modern science and created a unique style in which the emphasis on subjectivity makes present the concept of subject and object, since both share a mutual relationship building, in which reality is constructed. On the other hand, the dialogic approach proposed by Ivana Marková offers a useful apparatus for understanding the social constitution of the individuals who live in educational contexts. The theoretical convergence of approaches discussed in this paper contributed to the identification of the TSR as a part of scientific knowledge that fosters analysis of teacher policies, by providing constructs to study the symbolization expressed in the documents, as well as those circulating in the different groups through conversations and practices. 
Keywords: Social Representations. Education. Procedural. Dialogicity. Theoretical approaches. Teachers policies.

\section{Resumen}

Las discusiones que componen este artículo están destinadas a proporcionar un análisis del potencial que la teoría de las representaciones sociales (TRS) ofrece a las investigaciones sobre políticas docentes. A través de la consideración de dos de los enfoques teóricos y metodológicos que conforman el campo de los estudios sobre las representaciones sociales, hemos tratado de identificar convergencias teóricas e de investigación que instrumentalizasen los estudios de las políticas públicas. Estudios embazados en el enfoque de procedimiento perturbaron los paradigmas de la ciencia moderna y crearon un estilo único en el que el énfasis en la subjetividad hace presente el concepto de sujeto y objeto, ya que ambos comparten una relación mutua, en la que se construye la realidad. Por otro lado, el enfoque dialógico propuesto por Ivana Marková ofrece un aparato útil para la comprensión de la constitución social de las personas que viven en contextos educativos. La convergencia teórica de enfoques analizados contribuyó a la identificación de las TRS como parte del conocimiento científico que fomenta el análisis de las políticas docentes, proporcionando construcciones para estudiar la simbolización expresada en los documentos, así como aquellos que circulan por los diferentes grupos a través de charlas y prácticas.

Palabras clave: Representaciones Sociales. Educación. Procedimiento. Dialogicidad. Enfoques teóricos. Políticas docentes.

\section{Introdução}

Inspirado pela obra de Serge Moscovici e de Ivana Marková, este trabalho buscou as relações entre a Teoria das Representações Sociais (TRS) e os estudos em políticas docentes. A perspectiva psicossocial 
proposta por Moscovici é incrementada em complexidade ao receber os estímulos da abordagem dialógica. O desenvolvimento alcançado pela TRS na Psicologia Social, em seus variados âmbitos, ultrapassou a fronteira deste campo da Psicologia e passou a oferecer a outras áreas, entre elas a da Educação, um aparato analítico que enriquece e expande os estudos psicossociais nesses campos.

As contribuições da TRS para as pesquisas em políticas educacionais motivaram a redação deste artigo que tem o intuito de debater duas das abordagens teórico-metodológicas que compõem o domínio dos estudos em representações sociais. Ao apresentar as especificidades de cada perspectiva, buscou-se proporcionar uma análise acerca da fecundidade da TRS para as investigações que têm o objetivo de compreender como as indissociáveis dimensões subjetiva e social afetam os variados contextos educativos e contribuem para a elaboração de políticas docentes.

Para tal, contribuições de Serge Moscovici foram revisitadas, o que permitiu desvelar, por um lado, as reminiscências do autor da TRS e, por outro, ofertar ao leitor filigramas singulares da sua posição de sujeito pela sua palavra, estilo e sua subjetividade. A ontologia dialógica de Ivana Marková é apresentada em sequência, tendo em vista a sua proposição de uma teoria do conhecimento social baseada na dialogicidade e na TRS.

O artigo, portanto, desenvolve uma trajetória em um único sentido, em duas vias sobrepostas. Ao traçar um caminho do sujeito singular às instituições, da subjetividade de Serge Moscovici ao estudo das políticas por meio da TRS, perpassando a tríade dialógica, o texto visa oferecer um debate acerca desse profícuo instrumental teórico para a compreensão da constituição social dos sujeitos que convivem nos contextos educacionais, ao assumir a tônica das políticas docentes.

\section{Sujeito Moscovici: errância de presença/ausência}

$\mathrm{Na}$ empreitada de desvelar as reminiscências do pesquisador que inquietou os paradigmas da ciência moderna e que retomou com originalidade o conhecimento do senso comum emancipando-o do científico 
e atribuindo-lhe legitimidade para a compreensão dos fenômenos humanos, cientificamente Moscovici (1978) construiu um viés tendo como base epistemológica a Psicologia Social, para compreender porque o autor sinaliza uma fundante justificativa para a complexidade da teoria quando ao salientar e justificar a proposição do fato de a representação social ser um conceito híbrido, não pertencente a uma única área disciplinar de conhecimento, visto sua origem vincular-se tanto à Sociologia quanto à Psicologia, por fornecer indícios para uma leitura psicossocial do objeto a ser investigado.

Pode-se dizer que a representação social, expressa uma espécie de saber prático de como, os sujeitos em processos de interação com outros, sentem, assimilam, aprendem e interpretam o mundo, porquanto e como são produzidos coletivamente por práticas e discursos sociais, inscritos no decorrer das interações no cotidiano, algumas delas linguísticas. É possível pontuar que, para o sujeito, o produto assim gerado tem uma base cognitiva e afetiva e, justificam como pesquisadores que investigam, sob esse foco psicossocial, demonstrem preocupação em como integrar dimensões afetivas e cognitivas na análise das representações sociais.

O presente artigo ressalta dois argumentos relativos à complexidade conceptual de que se reveste a abordagem processual defendida por Moscovici (1978): o primeiro refere-se ao fato da representação social ser um conceito híbrido, e seu pertencimento ser singular em duas áreas de conhecimento, quais sejam, a Sociologia e a Psicologia - o que permite pontuar que as representações sociais têm seus fundamentos epistêmicos no psicossocial. O outro argumento é que já se percebe um exercício intelectual no sentido de engendrar conceitos advindos de outras áreas de conhecimento em busca das interfaces teóricas com outros saberes e conhecimentos, numa tentativa de expandir seu campo de argumentação.

Pode-se inferir, de acordo com Moscovici (1990), para a pesquisa educacional ter maior impacto sobre a prática educativa ela precisa adotar "um olhar psicossocial", de um lado, preenchendo o sujeito social com seu mundo interior e, de outro, restituir o sujeito individual ao mundo social. Adianta Moscovici (1978, p. 307) que "as representações sociais 
estão relacionadas ao pensamento simbólico e a toda forma de vida mental que pressupõe linguagem". A atividade representativa constitui, portanto, um processo psíquico que permite ao sujeito tornar presente em seu universo subjetivo, interior ou não, seja um objeto distante ou ainda para ele ausente.

Uma vez esclarecida a natureza psicológica das representações, Moscovici (1978) passa a analisar, mais especificamente, sua natureza social. O autor avançou no construto das RS quando teorizou que o significante "representação social", remete a alguma concepção já presente socialmente, a uma ideia de diferenciação já produzida nas redes pessoais e interações do sujeito.

O sujeito na sua atividade representativa não reproduz passivamente, mas reconstrói o objeto e se constitui, nesse processo, como sujeito socialmente situado. Assim, as RS se constituem em sistemas de referência através dos quais cada um de nós (re)classifica pessoas e/ou grupos e (re)interpreta os acontecimentos do seu cotidiano.

Pelo exposto, as representações de um objeto são sempre sociais porque passam por um processo de constituição, derivado de encadeamentos de processos sociais que acontecem no cotidiano do sujeito. Serge Moscovici enfatiza a influência da comunicação no processo de construção das representações sociais. Nessa lógica, faz-se pertinente acrescentar que, o autor, em sua discussão epistemológica propõe que a representação é estruturada em três dimensões: imagem, atitude e informação. Em primeiro lugar, uma representação é organizada por imagens, as quais expressam iconicamente o objeto representado. A atitude corresponde à orientação global, favorável ou desfavorável ao objeto da representação, relacionando-se a uma escolha, orientada por experiências e valores do sujeito, a partir do que apreendeu em seu grupo de pertença a atribuir ao objeto. A atitude é a mais frequente das dimensões citadas porque uma pessoa representa alguma coisa em função da posição que adota. A terceira dimensão, a informação expressa como o grupo organiza os conhecimentos a respeito do objeto. Essas três dimensões do campo da representação social formam uma amálgama reveladora dos saberes, afetos e 
valores articulados que se constituem de forma dinâmica, afetiva, racional e afetivamente, presentificados na vida cotidiana do sujeito. Observa-se pela construção teórica de Moscovici que a vida cotidiana situa o entorno do senso comum, instituído a partir das modalidades de comunicação, e nesse tear a representação social se revela mesmo sabendo-se que ela se faz presente e ausente, que em frações de segundo, escapa, como se fosse um véu que mostra o que oculta quando se expressa ou se faz presente.

A teoria das representações sociais atribui ao sujeito um lugar e posição no processo da sua própria subjetivação e na interação com o outro. É nesse sentido que Jodelet no seu texto "O movimento de retorno ao sujeito e a abordagem das representações sociais" (2009) propõe um quadro analítico que permite a autora situar o estudo das representações sociais no campo da subjetividade e delimita as três esferas de pertença das representações sociais além de definir o estilo de cada uma das esferas". A figura 1 demonstra a interseção:

Figura 1 - As esferas de pertença das representações sociais

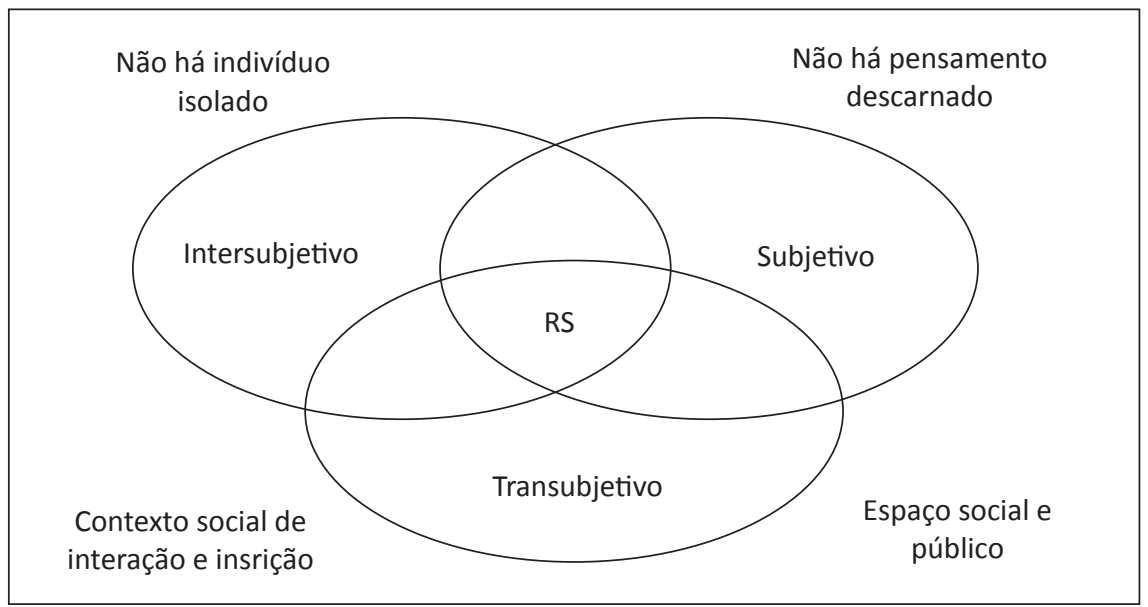

Fonte: Jodelel (2009, p. 695). 
Dessa perspectiva, decorre a pertinência de se pensar que o indivíduo fica/é engendrado pelas inter-relações nas quais se constrói e se reconstrói, subjetivamente em seu cotidiano.

Para subsidiar este escrito, foram pesquisadas algumas obras, mas a central dessa pesquisa teórica foi a obra literária "Crônica dos Anos Errantes" (Années Égarées), de 2005b, na qual Moscovici narra sua infância, marcada por ser judeu, e sua juventude na qual o medo, a solidão e a insegurança embalam suas reminiscências de sujeito em construção. "Anos errantes" remonta aos anos da segunda guerra mundial, período no qual o autor vivenciou intensamente, como outros a barbárie desse período.

O construto sujeito proposto por Lacan (1998) opera com a hipótese do inconsciente, sem devastar a dimensão de saber que o sujeito tem, embora seja um saber não-sabido. Essa conceituação de sujeito faz com que o autor se pronuncie sobre um sujeito essencialmente dividido. Nesse aspecto, é possível afirmar que o dizer de Moscovici não foi de todo posto, que restou algo a dizer. É nessa lógica a ele contemporânea que Moscovici (1961) funda a teoria das representações sociais (TRS), retoma o conceito de sujeito prevalecente, analisa e propõe o seu, inspirando uma nova abordagem da subjetividade no campo psicossocial. As relações de Moscovici com as representações sociais são como a imagem do tecelão em sua obra, alguns fios parecem partidos, outros estão unidos desenhando em seu trajeto uma peça necessariamente interminável.

É certo que este texto escapa em grande medida, o sujeito Moscovici, todavia, como todo investimento libidinal, há arquivos incandescentes a serem achados, ajustados, arremates a serem feitos, tramas desejantes a serem reveladas, vez que o teórico se encontra no lugar do sujeito da falta. Moscovici (2005) informa que quando criança leu Haggadah ${ }^{1}$, livro que fala da dignidade do sujeito de se emancipar da opressão, é um manifesto de liberdade, cada letra falada e escrita e

1 Livro que conta a saída do Egito e que é lido na noite de Páscoa. 
salmodiada exprime pulsão de vida e de morte. Moscovici cunha: uma vez apreendida, ela se inscreve no coração e não se apaga jamais. E nessa constituição Moscovici se estrutura na condição de sujeito presente/ ausente.

\section{Do sujeito moscoviciano à ontologia dialógica da TRS: uma contribuição para os estudos educacionais}

O breve debate desenvolvido acerca da perspectiva dialógica proposta por Ivana Marková à TRS não se encerra no contexto da Psicologia, mas busca ultrapassar fronteiras, uma vez que foi motivado por investigações desenvolvidas no campo educacional. Nesse sentido, buscou-se identificar e discutir elementos da Psicologia Social que pudessem colaborar para a formação e para o trabalho docentes.

Vale reiterar que os estudos em Educação, sobretudo no âmbito brasileiro, têm se favorecido das contribuições da TRS para investigar as simbolizações e as ações desenvolvidas em contextos educacionais. A teoria, que possui hoje pouco mais de meio século, oferece um instrumental teórico profícuo para as pesquisas que buscam compreender o conhecimento construído no cotidiano, nas múltiplas dimensões que compõem os universos subjetivo e social.

Desde a obra seminal "La Psychanalyse, son image, son public" de Serge Moscovici, publicada em 1961, a TRS avançou e construiu um corpus que pode ser identificado a partir de variados enfoques. O presente artigo abraça, portanto, o desafio de debater, ainda que muito brevemente, um desses enfoques: a sofisticada proposta de Ivana Marková de desenvolver uma teoria de conhecimento social baseada na dialogicidade e na TRS.

Ao integrar o conceito de diálogo ao de representações sociais, Marková oferece à TRS uma abordagem que assume a dialogicidade como condição sine qua non da mente humana. Importante alertar que, apesar de dar destaque ao pensamento em oposições, a perspectiva dialógica desenvolvida por ela não nega ou exclui outras formas de pensamento. Em 
"Dialogicidade e representações sociais: as dinâmicas da mente", Marková (2006) sistematiza para o leitor a sua teoria do conhecimento social e afirma que o pensamento ocorre de diferentes maneiras, bem como toma caminhos distintos. Nas palavras da autora:

A ênfase no pensamento em oposições não deveria dar a impressão de que nós excluímos ou negamos outras formas de pensamento. $\mathrm{Na}$ realidade, $[. .$.$] o pensamento acontece de muitas maneiras diferentes$ e toma rotas diferentes. Por exemplo, alguns tipos de pensamento são analógicos, existe o pensamento indutivo e dedutivo, existem pensamentos científicos, artísticos e do tipo de senso comum; existem também pensamentos práticos e teóricos (2006, p. 94).

Ao considerar a multiplicidade de modos de pensar, Marková assinala que diferentes problemas requerem diferentes tipos de pensamentos. No entanto, centra sua atenção no pensamento em antinomias uma vez que identifica nelas a ferramenta conceitual fundamental para o desenvolvimento da teoria do conhecimento social.

Dado o propósito deste texto, e, tendo em vista a erudição dos escritos de Marková, o artigo se deterá em debater a definição de dialogicidade como a capacidade dos seres humanos de conceber, criar e comunicar em termos de alter. Significa dizer que se centrará nas discussões acerca da alteridade, ou da outredade.

Marková, em "Constitution of the self: intersubjectivity and dialogicality" (2003), analisa padrões da produção acadêmica sobre subjetividade para a consideração das dimensões do alter na intersubjetividade. $\mathrm{O}$ trânsito feito por Marková $(2003,2006)$ por variadas ontologias nos faz perceber os movimentos de distanciamento e aproximação da Psicologia Social das Ciências Naturais, das Ciências Sociais ou mesmo da Filosofia.

Como sublinhado pela estudiosa, a TRS adota uma posição epistemológica que defende que, para se considerar a problemática da subjetividade (e da intersubjetividade), o olhar deve se fixar na dupla mediação do sujeito social com o alter. Nesse sentido, o sujeito social da TRS 
volta-se para uma mudança epistemológica na concepção de sujeito e, por conseguinte, de ego.

A análise da autora acerca dos fenômenos da linguagem e da linguística, no que se refere à antinomia social/individual, oferece à TRS um sofisticado repertório que fomenta reflexões acerca da intersubjetividade. Em seu texto "Social identities and social representations: how are they related?", Marková (2007) ressalta a relevância da concepção tríade Ego-Alter-Objeto, que, em sua interpretação, constitui a unidade epistemológica da teoria das representações sociais. Nas palavras de Marková (2007, p. 230) “[...] A comunicação entre Ego e Alter é sempre sobre algo: o Ego e o Alter geram representações sociais de objetos de conhecimento (ou crença) conjuntamente, isto é, dialogicamente. [...] A tríade dialógica é multifacetada". Aclara a autora:

[...] O objeto de representação na concepção tríade não precisa necessariamente ser uma coisa, ele pode ser uma pessoa, um grupo, uma representação de si [self-representation], ou a representação de outra pessoa. [...] A interação entre Ego e Alter nunca é apenas uma troca de palavras em um diálogo envolvendo participantes co-presentes. Ela sempre envolve uma terceira-parte que não está presente, incluindo uma "terceira pessoa", um "outro virtual" (como amigos, pares e instituições), ou posicionando o eu [self] em relação a "outros" fisicamente ou simbolicamente co-presentes (p. 232).

Por outro lado, em "Dialogicidades e representações sociais: as dinâmicas da mente", a autora afirma que: "Cada situação dialógica envolve tipos diferentes de Alter-Ego” (2006, p. 218).

Por exemplo, o AlterEgo pode ser composto de o Eu-grupo específico; o Eu-outra pessoa; o Eu-nação; grupo comunidade, etc. Durante um único encontro, muitas relações dialógicas do Alter-Ego podem, simultaneamente, competir e entrar em confronto. Os participantes dialógicos trazem para o diálogo suas experiências presentes e suas tradições passadas, bem como as expectativas sobre os seus futuros. Eles podem escolher mudar suas prioridades. Eles podem perpetuar 
continuidades e criar 4 descontinuidades. Eles podem se concentrar neles mesmos e, acima de tudo, expressar seus próprios interesses. Alternativamente, eles podem se orientar em relação aos seus Alter (MARKOVÁ, 2006, p. 218).

Tal compreensão de alter deixa patente a potencialidade desta perspectiva da TRS para o campo da Educação. Nesse tocante, pode-se tomar como exemplo a relação entre o docente, seus alunos e o objeto de conhecimento que o professor busca ensinar. Para isso, o título da edição de 2015 do EDUCERE, "Formação de professores, complexidade e trabalho docente", é inspirador, uma vez que nele se encontram os elementos concretos para pensar sobre a teorização do conhecimento social de Marková (2006).

Tendo em conta que a tensão existente entre Ego-Alter-Objeto consiste na força que leva à mudança e à transformação das representações e, que a gênese das representações sociais é dinâmica e processual, podem-se encontrar na perspectiva de Marková (2006) os elementos básicos para aquilo que Mohamed Chaib (2015) propõe como uma pedagogia fundamentada na TRS, nomeadamente quando o autor sugere que esta teoria pode definir e explicar os processos de ensino e de aprendizagem.

Nesses termos, a complexidade do saber docente, adquirido tanto em seus processos iniciais de formação, quanto em sua prática em sala de aula, bem como em sua formação contínua, se institui a partir do processo relacional do professor com o seu Alter por excelência, ou seja, o aluno, bem como com seus outros Alter, seus colegas professores, a mídia, a rede de ensino, a sua família.

A tensão que se constata entre tantos alter ${ }^{2}$ é explicada pela concepção tríade, haja vista a multiplicidade de outros que se relacionam com o ego e com o objeto. São, portanto, muitos os outros presentes, na relação entre o professor, o aluno e o objeto de conhecimento. Esses outros, nem

2 Vale salientar que Marková (2006) entende Alter como Outros, no plural, e não como Outro, no singular. 
sempre contemplados nas formações docentes, ou nas políticas públicas, não deixam, contudo, de povoar a sala de aula.

Traz-se a essa discussão um assunto complementar. Ocorre que Moscovici (2011) já deixava algumas pistas, em seu modelo genético de mudança social, quando se dedicou ao estudo das minorias ativas e do reconhecimento social. O modelo genético de mudança social foi analisado por ele com base na dinâmica dos processos de Alter-Ego-Objeto, na medida em que, para Moscovici, o poder da minoria ativa é o de influenciar e o de transformar a maioria mediante um comportamento consistente, conduzindo a maioria a avaliar sua postura frente o objeto de conhecimento.

Nesse sentido, a TRS no que propicia uma alternativa para o esquema da tríade dialógica Ego-Alter-Objeto, surge como alternativa à noção cartesiana que tanto influenciou a Psicologia e que, pela afinidade presente entre os campos disciplinares, subsidiou as teorias educacionais. Significa dizer que, com a tríade dialógica, a TRS traz à tona a possibilidade de pensar os docentes como grupos ativos na produção de um conhecimento complexo.

Se o propósito de avanço social por meio do conhecimento é o que motiva e orienta a educação, encontramos nessa teoria do conhecimento social as unidades elementares para o planejamento de uma formação e trabalho docente que levem em conta a complexidade da profissão do professor, uma vez que essa é essencialmente relacional: a relação do professor com o conteúdo, com o aluno e com a multiplicidade de outros que o constituem enquanto docente.

\section{Convergências teóricas: um diálogo com o campo das políticas docentes}

Compreender que as pesquisas em representações sociais contribuem para o aprofundamento dos estudos em políticas públicas implica em assumir que são nos espaços da criação, da construção, da divulgação e da práxis que os textos políticos operam diferentes influências, haja vista o contexto econômico, político, social e cultural de uma dada sociedade. 
A seminal abordagem de Serge Moscovici associada à perspectiva dialógica proposta por Ivana Marková contribuem sobremaneira para a compreensão daquilo que o criador da teoria nomeou como "um corpo organizado de conhecimento e uma das atividades psíquicas graças às quais os homens tornam a realidade física e social inteligível" (MOSCOVICI, 2012, p. 28).

O fenômeno comunicacional é o objeto de análise de ambos os autores, dado que as representações sociais se constituem por meio da linguagem. Nas palavras de Lahlou (2003, p. 41), “[...] É na língua que procuramos os objetos do mundo, uma vez que a língua é uma memória social que, por meio de sua rede semântica, sedimenta as visões do mundo produzidas pela cultura". Complementarmente, esse autor explica que "as ligações entre as palavras representam as conexões entre ideias" (p. 41). Do que podemos afirmar não existir discurso ou texto neutro.

A convergência teórica das abordagens discutidas neste artigo contribui para a identificação da TRS enquanto uma vertente do conhecimento científico que fomenta a análise das políticas docentes, por oferecer um instrumental profícuo para o estudo das simbolizações expressas nos documentos, bem como aquelas circulantes nos diferentes grupos por meio das conversações e das práticas.

No que tange à comunicação social e a sua relação com as políticas públicas no campo educacional, mostra-se imperativo ter em conta aquilo que Ball (2001, p. 100) denominou como o "surgimento de um novo paradigma de governo educacional". O autor questiona: "até que ponto estamos a assistir ao desaparecimento gradual da concepção de políticas específicas do Estado Nação nos campos econômicos, social e educativo", explicando as políticas nacionais como um processo de 'bricolagem', ou seja, "um constante processo de empréstimo e cópia de fragmentos e partes de ideias de outros contextos, de uso e melhoria das abordagens locais já tentadas e testadas" (BALL, 2001, p. 102). 
O diagnóstico de $\mathrm{Ball}^{3}$ alerta para a necessidade de debates de fôlego acerca da produção e dos efeitos das políticas públicas no campo educacional. Soma-se a isso a afirmação de Shiroma, Campos e Garcia sobre as reformas educacionais. Para elas, os organismos multilaterais, como o Banco Mundial (BM), Organização das Nações Unidas para a Educação, a Ciência e a Cultura (UNESCO), Organização para a Cooperação e Desenvolvimento Econômico (OCDE), "não apenas prescreviam as orientações a serem adotadas [...] produziam o discurso 'justificador' das reformas" (2005, p. 430).

O estudo das diversas representações que, apesar de muitas vezes concorrentes e conflitantes, as quais convivem na 'bricolagem' de discursos constantes dos documentos permite não apenas a avaliação das motivações e dos possíveis efeitos das políticas públicas, mas também a análise das possibilidades de significação e de ressignificação dos sujeitos sociais afetados por elas. No mesmo sentido, a referida teoria vem permitindo aferir, ainda que de modo preliminar, os presumíveis impactos que diferentes políticas geram em determinados espaços e tempos.

\section{Referências}

BALL, S. J. Diretrizes políticas globais e relações políticas locais em educação. Currículo sem Fronteiras, v. 1, n. 2, p. 99-116, jul./dez. 2001. Disponível em: $\langle$ http://www.curriculosemfronteiras.org/vol1iss2articles/ball.pdf >. Acesso em: 15 mar. 2015.

CHAIB, M. Social representations, subjectivity and learning. Cadernos de Pesquisa, São Paulo, v.45, n.156, p.359-371, abr./jun. 2015.

JODELET, D. O movimento de retorno ao sujeito e a abordagem das representações sociais. Sociedade e Estado, Brasília, DF, v. 24, n. 3, p. 679-712, set./dez. 2009. Disponível em: <http://www.scielo.br/pdf/se/v24n3/04.pdf >. Acesso em: 15 ago. 2016.

3 Nesse tocante, uma debate que merece alongado estudo reside na busca de articulação entre a noção de comunidades epistêmicas e representações sociais. 
LACAN, J. Subversão do sujeito e dialética do desejo no inconsciente freudiano. In: LACAN, J. Escritos. Trad. Vera Ribeiro. Rio de Janeiro: Zahar, 1998. p. 93-103.

LAHLOU, S. L'exploration des représentations sociales à partir des dictionnaires. In: ABRIC, J.-C. (Dir.), Méthodes d'étude des représentations sociales. Ramonville SaintAgne: Érès, 2003. p. 37-58.

MARKOVÁ, I. Constitution of the self: intersubjectivity and diologicality. Culture \& Psychology, v. 9, n. 3, p. 249-259, 2003.

MARKOVÁ, I. Dialogicidade e representações sociais: as dinâmicas da mente. Trad. Hélio Magri Filho. Petrópolis, RJ: Vozes, 2006.

MARKOVÁ, I. Social Identities and Social Representations: how are they related? In: MOLONEY, G.; WALKER. I. (Eds). Social Representations and Identity: content, process and power. London, Palgrave Macmillan, 2007. p. 215-236.

MARKOVÁ, I.; MOSCOVICI, S. Ideias e seu desenvolvimento: um diálogo entre Serge Moscovici e Ivana Marková. In: MOSCOVICI, S. Representações sociais: investigações em psicologia social. Rio de Janeiro: Vozes, 2003. p. 305-388.

MOSCOVICI, S. La psychanalyse, son image et son public. Paris: Presses Universitaires de France, 1961.

MOSCOVICI, S. A representação social da psicanálise. Trad. Álvaro Cabral. Rio de Janeiro: Zahar Editores, 1978.

MOSCOVICI, S. Representações sociais: investigações em psicologia social; editado em inglês por Gerard Duveen; traduzido do inglês por Pedrinho A. Guareschi Petrópolis, RJ: Vozes, 2003.

MOSCOVICI, S. Sobre a subjetividade social. Trad. de Lilian Ulup. In: SÁ, C. Memória, imaginário e representações sociais. Rio de Janeiro: Museu da República, 2005. p. 11-62.

MOSCOVICI, S. Psicologia das minorias ativas. Tradução do Grupo de Leitura "Ideologia, Comunicação e Representações Sociais"; responsável Pedrinho Guareschi. Petrópolis, RJ: Vozes, 2011. 
MOSCOVICI, S. Psicanálise, sua imagem e seu público. Tradução de Sonia Fuhrmann. Petrópolis, RJ: Vozes, 2012.

MOSCOVICI, S.; MARKOVÁ, I. Presenting social representations: a conversation. Culture \& Society, v. 4, n. 3, p.371-410, 1998.

SHIROMA, E. O.; CAMPOS, R. F.; GARCIA, R. M. Decifrar textos para compreender a política: subsídios teórico-metodológicos para análise de documentos. Perspectiva, Florianópolis, v. 23, n. 2, p. 427-446, jul./dez. 2005. Disponível em: <https://periodicos.ufsc.br/index.php/perspectiva/article/view/9769>. Acesso em: 15 ago. 2016.

Recebido: 15/06/2016

Received: 06/15/2016

Aprovado: 10/08/2016 Approved: 08/10/2016 
